\title{
Kant on Perception, Experience and Judgements Thereof
}

\author{
BANAFSHEH BEIZAEI \\ New York University \\ Email: bb2593@nyu.edu
}

\begin{abstract}
It is commonly thought that the distinction between subjectively valid judgements of perception and objectively valid judgements of experience in the Prolegomena is not consistent with the account of judgement Kant offers in the B Deduction, according to which a judgement is 'nothing other than the way to bring given cognitions to the objective unity of apperception'. Contrary to this view, I argue that the Prolegomena distinction maps closely onto that drawn between the mathematical and dynamical principles in the System of Principles: Kant's account of the Prolegomena distinction strongly suggests that it is the Analogies of Experience that make it possible for judgements of perception to give rise to judgements of experience. This means that judgements of perception are objectively valid with regard to the quantity and quality of objects, and subjectively valid with regard to the relation they posit between objects. If that is the case, then the notion of a judgement of perception is consistent with the B Deduction account of judgement.
\end{abstract}

Keywords: perception, experience, judgement, objectivity, appearance, judgement of perception, judgement of experience, System of Principles, Prolegomena

\section{Introduction}

In the Prolegomena to Any Future Metaphysics, written between the publication of the first and second editions of the Critique of Pure Reason (CPR), Kant draws a distinction between two types of empirical judgements: judgements of perception and judgements of experience. The former are only subjectively valid: 'they hold only for us, i.e., for our subject', while the latter have objective validity: we 'intend that they should be valid at all times for us and for everyone else'. Judgements 
of perception 'do not require the pure concepts of the understanding, but only the logical connection of perceptions', while judgements of experience require 'in addition special concepts originally generated in the understanding' $(\$ 18,4: 298)$. $^{\mathrm{I}}$

The Prolegomena distinction is not mentioned in either edition of the $C P R$. In the B Deduction, Kant draws a distinction between the subjective associations of imagination on the one hand, and the objective unity of apperception, which attaches to all judgements, on the other (\$I9, BI 42). This has led some commentators to conclude that the B Deduction abandons the distinction drawn in the Prolegomena in favour of a more unified account of judgements, in which they are all objectively valid. Paul Guyer argues that the distinction between judgements of perception and judgements of experience is inherently at odds with the CPR assumption that any form of apperception presupposes the categories (Guyer 1987: гог). In the first edition of his Kant's Transcendental Idealism, Henry Allison argues that the Prolegomena distinction is replaced in the $C P R$ by the distinction between subjective and objective unities of consciousness (Allison I983: I48-53). Altering his position in the book's revised and enlarged edition, Allison aligns himself with Ernst Cassirer, who argued that Kant's notion of a judgement of perception 'is only meant to be a methodologically constructed limiting-case', to provide a contrast to the notion of scientific objectivity (Allison 2004: I79-82; Cassirer 1953: 245-6). Norman Kemp Smith also argued that the distinction is 'thoroughly misleading', and fundamentally at odds with Kant's fully developed critical system (Smith I9I 8: 288-9).

In this paper I aim to salvage the much-maligned Prolegomena distinction. I will argue that, with help from the System of Principles, the Prolegomena distinction can, indeed, be reconciled with the B Deduction account of judgement. To that end, I will begin with an overview of Kant's treatment of the notion of objectivity, which is central to the distinction between perception and experience in his system (section 2). I will go on to look at the System of Principles in the CPR, arguing that the mathematical principles (Axioms of Intuition and Anticipations of Perception) involve the generation of perception from empirical intuition, while the Analogies of Experience involve the generation of experience from perception (section 3). I will then look at Kant's account of the distinction between judgements of perception and judgements of experience in the Prolegomena, and argue that his account of the distinction strongly suggests that the 'special concepts' required for making judgements of experience are those belonging to the relational 
categories (section 4). Finally, I will show that the framework I have developed allows us to circumvent the most common problem faced in reconciling the Prolegomena distinction with the account of judgement in the B Deduction (section 5).

\section{Overview: Objectivity and Determinacy}

In Kant's critical system, 'representation' is the umbrella term used for all mental states. Under 'representation' fall sensations, intuitions, concepts, cognitions and even judgements. Human intuitions are either pure or empirical. Pure intuition is the mere form of space and time, and empirical intuition is the spatiotemporal form 'filled in' with sensory matter. Concepts, which belong to the faculty of understanding, can also be pure or empirical. If pure, concepts are called categories. ${ }^{2}$ The categories are characterized as general rules of synthesis (BIO5), where synthesis is to be understood, in the most basic terms, as the process of combining and ordering complex representations into a unified whole. Together, space, time and the categories are the pure forms under which every object that can come before us must necessarily stand.

Intuitions, concepts and judgements are each characterized as 'objectively valid' at some point in the CPR. ${ }^{3}$ If one is to make sense of this seemingly indiscriminate usage, it has to be allowed that Kantian objectivity admits of gradations. In the lectures on logic transcribed by Jäsche, Kant characterizes the 'objective content' of cognitions in precisely these terms: degrees. Here, he distinguishes between various levels of cognition, allowing that it is only by means of concepts that we can 'understand' (verstehen) something $(9: 64-5) .^{4}$

In delineating these gradations of objectivity, I will draw on Kant's notion of determination (Bestimmung) in the transcendental sense (i.e. in the sense having to do with the mind's a priori contribution to cognition). ${ }^{5}$ Kant talks about transcendental determination in the Amphiboly section of the $C P R$, where he characterizes form as 'determination' and matter as 'the determinable in general' (A266/B322). ${ }^{6}$ In rough terms, then, to determine something in the transcendental sense is to impose a priori form on its matter. Again, according to Kant there are of course a number of a priori forms of experience: space, time and the categories. It must be the case, then, that determinacy (i.e. 'enformedness'), also admits of gradations. ${ }^{7}$

In the Transcendental Aesthetic, appearance is introduced as 'the undetermined object of an empirical intuition' ( $\left.\mathrm{B}_{34} / \mathrm{A}_{2} \mathrm{O}\right)$. There is, however, a more general sense in which 'appearance' is used in the 
transcendental idealist framework: even when the (originally indeterminate) object of empirical intuition is determinate, it is still 'only' an appearance in contrast to things in themselves. This fully determinate object of representation (i.e. appearance in the second sense) is a 'phenomenon'. ${ }^{8}$ At the most basic level, the object of a sensible intuition is indeterminate (or 'determinable') with regard to pure concepts of the understanding. 9 As the categories are 'concepts of an object in general', subsumption under the categories is necessary for the further determination of objects and their relations $\left(\mathrm{B}_{4} 48, \mathrm{~A}_{3} 3 / \mathrm{B}_{17} 6\right)$. As representations are synthesized, their objects go from being appearances (in the first sense) to being phenomena. ${ }^{\text {IO }}$ What is a composite of matter and form at one level of representation (intuition) can serve as matter at a higher level of representation (experience).

Now we can return to the discrete gradations of objectivity. As with the formal determinacy of objects, so with the objectivity of representations: the more formally determinate an object, the more objective its representation. The objectivity of a representation is, in other words, an indication of the extent to which its object is determined with regard to the a priori forms of experience. ${ }^{\text {II }}$ A fully objective representation would be an experience or empirical cognition. An entirely subjective representation, on the other hand, would be a sensation: ${ }^{\mathrm{I} 2}$ sensations are 'immediate' representations, meaning they are unprocessed by our cognitive apparatus (i.e. they are pure matter and formless). ${ }^{\mathrm{I}}{ }^{3}$ As the forms of experience are the a priori conditions of cognition for all discursive spatiotemporal intellects, objective validity can be understood, in the most general sense, as formal inter-subjective validity.

So far, we have established the following preliminary levels of objectivity and determination shown in the table.

\begin{tabular}{llllll}
\hline \hline $\begin{array}{l}\text { Level of } \\
\text { Objective } \\
\text { Validity }\end{array}$ & Representation & Form & Matter & Object & $\begin{array}{c}\text { Level of } \\
\text { Determination }\end{array}$ \\
\hline \hline I & Intuition & Space and time & Sensation & Appearance & I \\
2 & Experience & The categories & Intuition & Phenomena & 2 \\
\hline \hline
\end{tabular}

It should be clear that this purely formal notion of objectivity is a necessary but not sufficient condition of the empirical truth of cognitions, if by empirical truth we understand the agreement not only of the form 
but also of the content of cognition with the object to which it is related (A59-60). Objective validity is thus a negative criterion of empirical truth, and objectively valid empirical judgements are those that are capable of being true for everyone.

\section{A Priori Principles}

Kant characterizes the a priori principles of the understanding as 'principles of the objective determination of all representations' (B I42) and 'rules of the objective use of the categories' (B2OI). The categories are divided into two groups: the mathematical categories (quantity and quality) pertain to objects of intuition; the dynamical categories (relation and modality) concern the existence of the objects of intuition, 'in relation to each other or to the understanding' (BIIO). The a priori principles of the understanding, likewise, fall into two groups: the mathematical principles (Axioms of Intuition and Anticipations of Perception) and the dynamical principles (Analogies of Experience and Postulates of Empirical Thinking in General). ${ }^{\mathrm{I}}$

In a note added to the second edition of the System of Principles, Kant elaborates on the nature of the syntheses corresponding to these two kinds of principles:

All combination (conjunctio) is either composition (compositio) or connection (nexus). The former is the synthesis of a manifold of what does not necessarily belong to each other, as e.g., the two triangles into which a square is divided by the diagonal do not of themselves necessarily belong to each other, and of such a sort is the synthesis of the homogeneous in everything that can be considered mathematically (which synthesis can be further divided into that of aggregation and of coalition, of which the first is directed to extensive magnitudes and the second to intensive magnitudes). The second combination (nexus) is the synthesis of that which is manifold insofar as they necessarily belong to one another, as e.g. an accident belongs to some substance, or the effect to the cause - thus also as represented as unhomogeneous but yet as combined a priori, which combination, since it is not arbitrary, I call dynamical, since it concerns the combination of the existence of the manifold (which can again be divided into the physical combination of the appearances with one another and the metaphysical, their combination in the a priori faculty of cognition). (B2OI-2) 
The syntheses carried out in accordance with the first two categories thus compose the extensive and intensive magnitude of appearances (hence the mathematical principles are also characterized as 'constitutive'), while those carried out in accordance with the relational categories connect appearances (the dynamical principles are called 'regulative'). Note that according to the quoted passage, the connection of appearances in accordance with the dynamical principles contains a different kind of necessity than that which their mere composition does. Kant states that the mathematical principles are 'unconditionally necessary' in regard to possible experience, while the dynamical principles are necessary only 'under the condition of empirical thinking in an experience' (BI99/AI6). This is because it is formally necessary that every intuition have an extensive and intensive magnitude, while it is formally contingent whether the object of an intuition exists or not: ${ }^{\mathrm{I}}{ }^{5}$ according to the second Postulate, for something to exist, it must be 'connected with the material conditions of experience (of sensation)' (B266, my emphasis). ${ }^{16}$ Thus, it is only formally necessary that if an object exists, it stands in determinate relations with other existing objects. The dynamical principles concern a different kind of necessity than the mathematical ones because they presuppose the formally contingent existence of objects.

\section{Axioms of Intuition and Anticipations of Perception}

The Axioms of Intuition govern the synthesis by which an appearance is taken up into 'empirical consciousness', which is alternately referred to as perception (Wabrnehmung) (B207). The synthesis in accordance with the Axioms involves the combination of the homogeneous in the manifold of intuition, where 'the homogeneous' refers to the continuum of space and time in intuition. The Axioms tell us that all intuitions, as regards their spatiotemporal form, are extensive magnitudes: they are constituted through the successive addition of one homogeneous unit to another. The synthesis in accordance with the Axioms thus generates the representation of a determinate region of space and interval of time (i.e. an extensive magnitude) in the manifold of intuition.

The Anticipations of Perception are concerned not with the spatiotemporal in perception, but with what Kant calls 'the real' in them - the degree of the sensation by which the subject is affected. As I said earlier, sensation is a subjective representation - it is a modification of the state of the subject. Despite the subjective character of sensation, however, the Anticipations tell us that it can be cognized a priori that every sensation has a sensory content of a determinate degree (i.e. an intensive magnitude) which corresponds to the degree of influence of the objects of 
perception on sense. An absence of 'the real' in sensation would, thus, amount to the absence of all perception.

Together, the syntheses carried out in accordance with the first two principles - the synthesis of the form of the intuition and the synthesis of the 'real' in the intuition - yield perception: the first takes up empirical intuition into 'empirical consciousness' (i.e. into apprehension) by generating the representations of a determinate extensive magnitude, and the second 'anticipates' all perception as having an intensive magnitude corresponding to 'the real' in the object of perception. I will refer jointly to these two syntheses as the 'synthesis of apprehension', and understand perception to be apprehended empirical intuition.

\section{Analogies of Experience}

It is only in the Analogies of Experience that Kant starts speaking of experience (Erfahrung) in the System of Principles, and he repeatedly distinguishes it from perception, the subject of the previous two principles: he defines experience as the 'representation of a necessary connection of perceptions'; as 'empirical cognition, i.e. a cognition that determines an object through perceptions' (B2I8); and, finally, as 'the synthetic unity of perceptions' ( $\left.\mathrm{A}_{1} 83_{3} / \mathrm{B}_{22} 26\right)$. He goes on to characterize the Analogies as rules 'in accordance with which unity of experience is to arise from perceptions' (AI80/B223).

The Analogies, thus, represent the conditions that are necessary for perception (apprehended intuition) to yield experience. They are 'regulative' of intuition but 'constitutive' of experience (A664/B692). As was previously stated, Kant characterizes the dynamical principles as dealing with the existence and relations of objects (AI78/B22I). Recall from earlier that, according to the second Postulate, an object exists if it 'is connected with the material conditions of experience (of sensation)' (B266). Roughly, then, for an object to exist, it has to be connected to a sensory state. Kant makes it clear that this connection does not have to be immediate: an object exists so long as it is connected to the object of some sensory state in accordance with the Analogies (A225). Thus, insofar as their existence is concerned, all objects of experience stand in determinate dynamical relations to one another.

Kant says that the Analogies are 'rules of general time-determination' (B220). Accordingly, the Analogies present the rules in accordance with which all existing appearances ('objects of experience') stand in determinate time relations. The first Analogy states that substance 
(the persisting, underlying matter of all appearance) is the precondition of all temporal relations between objects of experience. The second Analogy states that all 'alteration' (i.e. the succession of one state by another in the same object) in objects of experience happens in accordance with the law of the connection of cause and effect, where the cause is a sufficient condition for the bringing about of the effect. The third Analogy, lastly, states that all objects of experience, insofar as they coexist in space, are in thoroughgoing causal interaction (immediately or mediately).

Kant says that experience, in contrast to perception, represents the 'relation in the existence of the manifold ... not as it is juxtaposed in time but as it is objectively in time' (B2 I9). Given that apprehension is always successive while appearances can coexist, there is a difference between the 'subjective' time of inner sense in which we apprehend intuitions and the 'objective' time in which objects of experience exist and interact with one another (cf. Watkins 2005: I89). The various states of an apprehended object might coexist, as do for example the different parts of a house, but they are apprehended successively in time. In other words, perception only presents the succession of states in the subject, not their priority or simultaneity in the object (B233, $\left.\mathrm{B}_{257}\right)$. Without the a priori synthesis of perceptions in accordance with the relational categories, it would not be possible to distinguish between subjective and objective time.

Thus the temporal relations of perceptions in apprehension do not necessarily correspond to the objective temporal relations that hold between actual appearances. This means that the synthesis of apprehension generates representations that are objective with respect to their extensive and intensive magnitudes, but subjective with regard to their temporal relations. We can thus say that perception is a partially objective representation. For a representation to be fully objective, it needs to represent the necessary connections that hold between objects of experience in accordance with the Analogies. ${ }^{17}$ This representation would be an empirical cognition, or experience. We can now fine-tune the preliminary table presented in section 2 (see p. 355 ).

\section{The Prolegomena Distinction}

The Prolegomena was written before the publication of the second edition of the CPR and is meant to offer an overview of that work. Its main purpose, as expounded in the preamble, is to answer the question: how is metaphysics possible? This question is tackled in several steps, each of which roughly corresponds to the Transcendental Aesthetic, 
Transcendental Analytic, Transcendental Dialectic and Doctrine of Method in the CPR. The second part, whose content roughly overlaps with that of the Transcendental Analytic, is concerned with the question: how is pure natural science possible? Later, Kant further clarifies the problem by reformulating the question as: 'how is it possible in general to cognize a priori the necessary conformity to law of things as objects of experience?' $(\mathbb{I} 7,4: 296)$.

The laws in question here are what Kant terms the 'universal laws of nature' ( I $5_{5}$ 4: 295), and they are quite different from empirical laws of nature, in that the latter can never be cognized a priori. The universal laws of nature, which comprise the content of pure natural science proper, 'exist fully a priori', are purely 'formal' and determine the existence of all objects of experience ( $(\mathrm{I} 5-\mathrm{I} 6,4: 295-6)$. Recall from the previous section that the Analogies determine the existence and relation of appearances a priori. Already, then, there is a strong indication that Kant is primarily concerned with the Analogies in the second part of the Prolegomena. The primacy of the Analogies will become more evident in the ensuing discussion of the Prolegomena account of empirical judgements.

Soon after his reformulation of the question at hand, Kant draws the distinction between judgements of perception and judgements of experience:

[A]lthough all judgements of experience are empirical, i.e., have their basis in the immediate perception of the senses, nonetheless the reverse is not the case, that therefore all empirical judgements are judgements of experience; rather, beyond the empirical and in general beyond what is given is sensory intuition, special concepts must be added, which have their origin completely a priori in the pure understanding, under which every perception can first be subsumed and then, by means of the same concepts transformed into experience.

Empirical judgements, insofar as they have objective validity, are judgements of experience; those, however, that are only subjectively valid I call mere judgements of perception. The latter do not require pure concepts of the understanding, but only the logical connection of perceptions in a thinking subject. But the former always demand, beyond the representations of sensory intuition, in addition special concepts originally generated in the understanding, which are precisely what make the judgements of experience objectively valid. (\$I 8, 4: 297-8) 
Judgements of perception are subjectively valid - that is to say, 'they hold good only for us, i.e., for our subject' (\$I 8, 4: 298), while judgements of experience have objective validity, which, Kant says, is equivalent to 'necessary universal validity', i.e., holding for everyone (\$I9, 4: 298). The main difference between the two types of judgement is that judgements of perception do not require pure concepts of understanding but 'only the logical connection of concepts', whereas judgements of experience require 'special concepts originally generated in the understanding'. The objective validity of judgements of experience is due to the latter's use of these special concepts of the understanding. All (empirical) judgements, Kant writes, are 'at first' mere judgements of perception, and 'only afterwards do we give them a new relation, namely to an object, and intend that the judgement should also be valid at all times for us and for everyone else' $(\$ I 8,4: 298) .{ }^{\mathrm{I}}$

I hope to show that a close reading of the Prolegomena makes it abundantly clear that the 'special concepts' that make objectively valid judgements of experience possible are those belonging to the category of relation (subsistence, causality, community). ${ }^{19}$ This would mean that the sense in which judgements of perception are subjective concerns the relation they posit between appearances. The necessity expressed in judgements of experience would, accordingly, concern the relation that holds between appearances in accordance with the Analogies.

\section{The Prolegomena Examples}

The first examples Kant provides for judgements of perception are 'the room is warm, the sugar sweet, the wormwood repugnant'. These judgements 'express only a relation of two sensations to the same subject, namely myself, and this only in my present state of perception, and are therefore not expected to be valid for the object' ( $\mathbb{1 9}$, 4: 299). The judgements in this set of examples can never become judgements of experience 'because they refer to mere feeling - which everyone acknowledges to be merely subjective and which must therefore never be attributed to the object' (\$I9n., 4: 299).

Kant's second and third examples of judgements of perception are ones that can become judgements of experience. Curiously, the two types of judgement in the second example are identical in their formulation: Kant says that in making the judgement 'The air is elastic', one could either mean it as a judgement of perception, in which case only two perceptions (in the subject) are related to one another; or one could mean it as a judgement of experience, in which case one requires that the relation of 
the perceptions 'be subject to a condition that makes it universally valid' $\left(\mathbb{I}\right.$ 19, 4: 299). ${ }^{20}$ In the third example, Kant contrasts the mere judgement of perception 'If the sun shines on the stone, it becomes warm' with the judgement of experience 'The sun warms the stone'. In the latter formulation, 'beyond the perception is added the understanding's concept of cause, which connects necessarily the concept of sunshine with that of heat' (\$20n., 4: 30I).

Kant characterizes the process through which the judgement of perception 'The air is elastic' is converted into a judgement of experience as follows:

Now before a judgement of experience can arise from a judgement of perception, it is first required: that the perception be subsumed under a concept of the understanding of this kind; e.g., the air belongs under the concept of cause, which determines the judgement about the air as hypothetical with respect to expansion. This expansion is represented not as belonging merely to my perception of the air in my state of perception or in several of my states or in the states of others, but as necessarily belonging to it, and the judgement: the air is elastic, becomes universally valid and thereby for the first time a judgement of experience, because certain judgements occur beforehand, which subsume the intuition of the air under the concept of cause and effect, and thereby determine the perceptions not merely with respect to each other in my subject, but with respect to the form of judging in general (here, the hypothetical), and in this way make the empirical judgement universally valid. (\$I9, 4: 300-I)

Kant writes that before a judgement of experience can arise from a judgement of perception, 'certain judgements must occur'. These judgements 'subsume the intuition of the air under the concept of cause and effect' and thus 'determine the perceptions ... with respect to the form of judging in general'. To subsume representations under the categories is thus to determine them with regard to the logical forms of judgement. This means that for a combination of concepts to be indeterminate with regard to the logical forms of judgement is for it to be indeterminate with regard to one of the categories. ${ }^{2 \mathrm{I}}$ In the judgement of perception 'The air is elastic', the representation of air is indeterminate with regard to the relational categories: we know this because Kant says it has to be subsumed under the concept of cause and effect in order to be determined with regard to the hypothetical form of judgement. 
The following is a reconstruction of the process described in the passage above, through which judgements of perception turn into judgements of experience.

We start with:

(I) Judgement of perception: The air is elastic.

Which, in view of a nominal definition of elasticity as 'expanding after compression', can be turned into:

(2) Judgement of perception: After air is compressed, it then expands (i.e. returns to its original volume).

The 'condition' of the judgement of perception (here, compression) is subsumed under the concept of cause. ${ }^{22}$ This gives us:

(3) Judgement of experience: If air is compressed (cause), it expands (effect).

Which can be turned into:

(4) Judgement of experience: The air is elastic.

I do not imagine Kant is suggesting that, in making a judgement of experience, we explicitly go through steps (I) to (4). The process outlined above seems, rather, to be what would paradigmatically be involved in making judgements of experience. While the intricacies of just what is involved in 'subsumption' under the category of relation are controversial and not the focus of this paper, Kant is in any case explicit here that the process would involve making 'certain judgements'. ${ }^{23}$

Thus it is subsumption under pure concepts (specifically, under those concepts belonging to the category of relation - more on this in the next section), and not the mere logical form of judgement, that gives us licence to characterize the connection of appearances in necessary and universal terms. ${ }^{24}$ Given that the logical forms of judgement belong to pure general logic and the categories to transcendental logic, this should not come as a surprise. In the $C P R$, pure general logic is described as 'abstracting from all empirical conditions under which our understanding is exercised', and dealing with 'the mere form of thinking' ( $\mathrm{A}_{53} / \mathrm{B}_{77}-\mathrm{A}_{54} / \mathrm{B}_{7} 8$ ). In contrast, transcendental logic is concerned with 'the origin of our 
cognitions of objects insofar as that cannot be ascribed to the objects' (B8o/A 56), i.e. 'with the part of our thought that has its origin solely in the understanding'; it supplies 'the principles without which no object can be thought at all' (A62/B87). Therefore, the logical forms of judgement, on their own, are not sufficient for 'introducing' a transcendental content into representations, that is, for determining them with respect to the categories. ${ }^{25}$

\section{'Special Concepts'}

As we saw, judgements of experience require 'special concepts' of the understanding. Now, as I argued in section 3, perceptions (i.e. apprehended intuitions) are indeterminate with respect to the category of relation. Likewise, the judgements of perception Kant lists in the second and third examples of the Prolegomena were shown to be indeterminate with regard to the relational categories. Clearly, then, the 'special concepts' required for making judgements of experience are those belonging to the category of relation. As we progress in the second part of the Prolegomena, it only becomes more evident that Kant takes all and only judgements of experience to utilize the concepts belonging to the category of relation. ${ }^{26}$ The Analogies, we saw in the previous section, make it possible for experience to arise from perception. They are, accordingly, what makes it possible for judgements of perception to give rise to judgements of experience. In his account of the Analogies in the Prolegomena Kant writes:

With respect to the relation of appearances, and indeed exclusive with regard to their existence, the determination of this relation is not mathematical but dynamical, and it can never be objectively valid, hence fit for experience, if it is not subject to a priori principles, which first make the cognition of experience possible with respect to that determination. Therefore, appearances must be subsumed under the concept of substance, which, as a concept of the thing itself, underlies all determination of existence; or second, insofar as a temporal sequence, i.e., an event is met with among the appearances, they must be subsumed under the concept of an effect in relation to a cause; or, insofar as coexistence is to be cognized objectively, i.e., through a judgement of experience, they must be subsumed under the concept of community (interaction): and so a priori principles underlie objectively valid, though empirical judgements, i.e., they underlie the possibility of experience insofar as it is supposed to connect objects in nature according to existence. 
These principles are the actual laws of nature, which can be called dynamical. $(\$ 25,4: 307)$

The passage quoted makes it clear that the determination of the existence of appearances is objectively valid only if it is 'subject to a priori principles', that is to say, subject to the Analogies (since these are the principles that deal with the existence and relation of appearances). All judgements of experience thus involve the subsumption of perceptions under concepts belonging to the category of relation. The Analogies are described as 'the actual laws of nature', and, given the description of nature as 'the whole object of all possible experience' ( $\left.\mathbb{I}_{17}, 4: 297\right)$, it is evident that the Analogies are the rules to which all judgements of experience conform. ${ }^{27}$ The empirical laws of nature (for example, Newton's universal law of gravitation), insofar as they carry with them an expression of necessity, are grounded in the Analogies as the universal a priori laws of nature. ${ }^{28}$

Corresponding to this account, we can further fine-tune the table developed in sections 2 and 3 (see p. 362 ).

\section{Two Kinds of Judgements of Perception}

Judgements of perception can legitimately only express the connection of perceptions, not the connection of the objects of perception. However, this does not mean that such judgements only ever express what Prauss (1971) terms 'subjective-private states' (as quoted in Longuenesse I998: I88). While the relation they posit between perceptions depends on phenomenal consciousness (and is, thus, only subjectively valid), the perceptions themselves can have objects other than the subject's own representations. It is difficult to see how judgements regarding subjectiveprivate states can ever be conferred with necessity and universality - i.e. hold for everyone, as judgements of experience do. Nonetheless, Kant makes it clear that at least some judgements of perception can be transformed into judgements of experience, and that, in fact, all judgements of experience are initially mere judgements of perception $\left(\mathbb{S}_{I} 8,4: 298\right)$. I suggest, therefore, that judgements of perception are about partially determinate appearances, in the sense laid out in section 3 : appearances determined with respect to their quantity and quality, but not with respect to their relations. Some judgements of perception (e.g. 'sugar tastes sweet') can never be turned into objectively valid judgements of experience. Others (e.g. 'if the sun shines on the stone, it grows warm') can, if the constituent perceptions are subsumed under the category of relation. 


\begin{tabular}{|c|c|c|c|c|c|}
\hline $\begin{array}{l}\text { Level of } \\
\text { Objective } \\
\text { Validity }\end{array}$ & Representation & Form & Matter & Object & $\begin{array}{c}\text { Level of } \\
\text { Determination }\end{array}$ \\
\hline I & Intuition & Space and time & Sensation & Appearance & I \\
\hline \multirow[t]{2}{*}{2} & $\begin{array}{l}\text { Perception } \\
\text { (apprehended } \\
\text { intuition) }\end{array}$ & $\begin{array}{l}\text { Extensive and } \\
\text { intensive } \\
\text { magnitudes }\end{array}$ & Intuition & $\begin{array}{l}\text { Partially determinate } \\
\text { appearance }\end{array}$ & 2 \\
\hline & $\begin{array}{l}\text { Judgement of } \\
\text { perception }\end{array}$ & Relation of concepts* & $\begin{array}{l}\text { Perception analysed } \\
\text { into concepts*** }\end{array}$ & & \\
\hline \multirow[t]{2}{*}{3} & Experience & Dynamical relations & Perception & $\begin{array}{l}\text { Phenomena (fully } \\
\text { determinate } \\
\text { appearance) }\end{array}$ & 3 \\
\hline & $\begin{array}{c}\text { Judgement of } \\
\text { experience }\end{array}$ & Relation of concepts & $\begin{array}{l}\text { Experience analysed } \\
\text { into concepts }\end{array}$ & & \\
\hline
\end{tabular}

*The relation of subject to predicate, ground to consequence, or part to whole, corresponding to the categorical, hypothetical, and disjunctive forms of judgement. Cf. A266/B322: 'In every judgement one can call the given concepts logical matter (for judgement), their relation (by means of the copula) the form of the judgement.' While the form of both judgements of perception and judgements of experience is the relation of concepts, only the latter are determinate with respect to the category of relation. * I am following Longuenesse's account of concept formation, according to which empirical concepts are generated through analysing synthesized representations through processes of reflection, comparison and abstraction (I998: ch. 6). 
Kant's first set of examples can be said to be judgements of feeling. While Kant does not elaborate any further on feeling (Gefübl) in the Prolegomena, select passages in the CPR provide helpful remarks. In the Transcendental Aesthetic Kant characterizes feeling as 'an effect of the sensation', and 'pleasant taste' as grounded in feeling (A29). He further characterizes 'colors, sounds, and warmth' as 'merely sensations and not intuitions', and thus not 'allow[ing] any object to be cognized, least of all a priori' (B44/A28). ${ }^{29}$ These accounts are roughly in keeping with the first set of Prolegomena examples, which describe, respectively, warmth, taste and displeasure. These cannot ever become judgements of experience - i.e. they will only ever express the subject's present state. As Longuenesse puts it, they 'attribute[e] to the object a predicate that really expresses a mere feeling' (I998: I73, note I3).

The second group of judgements of perception - those that can become judgements of experience - are more than mere judgements of feeling. I suggest they can be characterized as either (i) singular judgements; $;^{3 \circ}$ or (ii) inductive generalizations. ${ }^{3 \mathrm{I}}$

A singular judgement of perception is valid only for the subject and at the time of its utterance, since any lasting and inter-subjective validity would presuppose at least a permanently persisting substratum in which properties can inhere (and potentially the concepts of causality or community, if the judgement posits a necessary temporal sequence or coexistence). As was previously argued, just because a certain representation assumes the position of subject in a judgement does not mean that its object is thought of as determined with respect to the pure concept of substance: I can say 'The air is elastic' without having subsumed air under the pure concept of substance. In such a case, the judgement, though categorical, is not determinate with regard to the category of relation, which means the relation it posits is not objectively valid.

An inductive generalization would lay claim to what Kant characterizes in the $C P R$ as 'assumed or comparative universality', which only licenses one to say 'so far as we have observed until now, no exception has been found to this or that rule'. An objectively valid judgement of experience, however, lays claim to what Kant characterizes as 'strict universality', such that 'no exception at all is allowed to be possible' $\left(\mathrm{B}_{3}-5\right)$. Strict universality can never be derived empirically, which only ever supplies the grounds for comparative universality. Judgements of perception that express inductive generalizations thus can only lay claim to comparative universality, which lacks the a priori grounding that allows for 
strict universality. Ultimately, the relation such judgements posit is not objectively valid either.

\section{The Problem of the B Deduction}

In $\$ I9 in the B Deduction, Kant characterizes judgement as 'nothing other than the way to bring given cognitions to the objective unity of apperception' (BI4I). The logical form of judgement is thus identified with the form of the objective unity of apperception (OUA), that is, a consciousness that is able to relate to objects. Longuenesse observes that the form of judgement ' $\mathrm{do}[\mathrm{es}]$ not relate my states to myself, but marks to objects'. The form of judgement thus carries with it the 'norm' to be objectively valid - that is to say, capable of being true for everyone (I998: I86).

This might seem to imply that a judgement of perception is a contradiction in terms: Kant does, after all, emphasize that such judgements are only subjectively valid. The account of judgement in the B Deduction has led some commentators, foremost among them Allison, to argue that the Prolegomena distinction is abandoned in the second edition of the CPR in favour of the distinction between associations of the imagination, which are subjectively valid, and judgements, which are objectively valid (Allison I983: $148-53$ ). Here is what Kant has to say about the former in the B Deduction:

In accordance with [laws of association] I could only say 'When I carry a body, I feel a pressure of weight,' but not 'It, the body, is heavy,' which would be to say that these two representations are combined in the object, i.e., regardless of any difference in the condition of the subject, and are not merely found together in perception (however often as that might be repeated). $(\mathbb{S}$ I9, BI42)

The laws of association are a function of the imagination, and they ensure that 'empirical ideas that have frequently followed one another produce a habit in the mind such that when one idea is produced, the other also comes into being' (Anth, 7: I76). This is, of course, reminiscent of Hume's characterization of custom or habit as the basis of our belief in causal connections (1993: 28). In fact, Kant mentions the laws of association in connection with Hume in his preface to the Prolegomena. Here he observes that for Hume the notion of a necessary connection between cause and effect is 'really nothing but a bastard of the imagination, which, impregnated by experience, and having brought certain 
representations under the law of association, passes off the resulting subjective necessity (i.e., habit) for an objective necessity (from insight)' $(4: 258)$.

In the revised and enlarged second edition of Kant's Transcendental Idealism, Allison alters his position with regard to judgements of perception, arguing that there is no doctrinal change in Kant's account of judgement between the publications of the Prolegomena and the B edition of the CPR. Following Cassirer, he attributes a didactic role to the notion of judgements of perception, claiming Kant devised it simply in order to expose the shortcomings of the 'standard empiricist', that is, Humean, account of empirical judgement (cf. Cassirer I953: 245-6). Allison goes on to argue, however, that the role of judgements of perception in the Prolegomena is not solely didactic, as Kant explicitly characterizes such judgements as 'the first stage in a cognitive process'. The seeming incompatibility between the B Deduction account of judgement and the Prolegomena distinction is finally attributed to the Prolegomena's 'particular goal and method', that is to say, its analytic (as opposed to synthetic) method, and its function as merely 'preparatory' for those wishing to become familiar with the critical system (Allison 2004: I79-82; cf. 201 5: 303-4). ${ }^{32}$

I believe the framework developed in this paper provides an alternative to both Allison's original and revised positions, and has the advantage of neither (i) attributing doctrinal confusion or a change of heart to Kant (as per Allison's first position), nor (ii) explaining away the apparent tension between the B Deduction and the Prolegomena by an appeal to pragmatic considerations on Kant's part (as per Allison's revised position).

If we allow, as I have argued, that appearances admit of degrees of determination, and that the mere form of judgement is not sufficient for the assertion of a necessary and universal connection between appearances, then we have to allow that there can be judgements that are not fully objective (i.e. judgements of perception). However, because (as $\$$ I9 in the B Deduction makes clear) the form of all judgements is the form of the OUA, judgements of perception, in cases where they are not judgements of feeling, can become judgements of experience: as judgements, they carry with them the 'norm' to achieve full objective validity.

On the other hand, subjective associations of the imagination can never give rise to universal rules. They are, properly speaking, mere expressions of the subject's representational states, and are thus not truth-valued 
(cf. Allison 2004: 88). Of course, it is consistent to argue that judgements of perception utilize empirical associations, habitually produced by the imagination, in asserting a connection between appearances (cf. Höffe I994: 74). In such a case, however, they would not be mere associations of the imagination: their form would be the form of the OUA, which carries with it the synthesis of apprehension. Strictly speaking, then, in the absence of the OUA, mere associations of the imagination would only be able to express a relation between unprocessed representations.

Unlike what Cassirer and Allison assert, then, it is not judgements of perception but subjective associations of the imagination that Kant uses didactically as 'a methodologically constructed limiting case', meant to 'throw light upon the newly gained concept of scientific objectivity by force of contrast' (Cassirer 1953: 245-6). As Longuenesse puts it, the distinction between subjective associations of imagination and objective judgements is not a distinction between two types of empirical judgement (as the Prolegomena distinction is) but between two proposed origins of empirical judgement (I998: I88). The first would be something akin to the 'bundle theory' offered by Hume, wherein there is no unified subject of experience, only associated representations. These associations, even if expressed in the form of judgements, would never have license to posit strict universality. The second would be Kant's account of the OUA as present in the form of all judgements. The OUA drives and makes possible the progression from judgements of perception into judgements of experience, which alone admit of strict universality. ${ }^{33}$

\section{Notes}

I I will follow the practice of citing the first Critique by giving the page number for the first edition of $\mathrm{I}_{78} \mathrm{I}$ (A) followed by the page number for the second edition of $\mathrm{I}_{7} 87$ (B). I will refer to Kant's other works by the volume and page number in the Akademie edition (I902- ). All translations are from the Cambridge edition of the works of Immanuel Kant, edited by P. Guyer and A. Wood (I99I-). For convenience, I will use in-text citation for Kant's works.

2 Note that my concern in this paper is solely with empirical theoretical cognition. There are pure concepts of practical cognition (those of morality) and pure concepts of non-empirical theoretical cognition (those of mathematics) that I am not considering here.

3 In the Transcendental Aesthetic, pure intuitions (space and time) are characterized as objectively valid with regard to appearances ( $\left.\mathrm{B}_{44} / \mathrm{A}_{2} 8, \mathrm{~A}_{35} / \mathrm{B}_{52}\right)$. In the Transcendental Analytic, the same is said of the pure concepts of the understanding (A90, BI26, A97) and judgements (BI4I, BI68).

4 I take it that here, as in the taxonomy of the Stufenleiter in the Transcendental Dialectic in the CPR $\left(\mathrm{A}_{32} 20 / \mathrm{B}_{377}\right)$, Kant is using the term 'cognition' more liberally than in the technical sense laid out in the B Deduction $\left(\mathrm{B}_{4} 47\right)$, to mean all representations that are objective to any degree. 
5 I make this distinction because Kant speaks of determination in a non-transcendental sense as well. The principle of complete determination, for example, states that all objects are determinate with regard to every possible predicate $\left(\mathrm{A}_{572} / \mathrm{B} 600\right)$. While the principle itself is supposed to be a priori, the particular predicates that are instantiated in particular objects are not.

6 Note that the Kantian usage of the terms 'determinate' and 'determinable' is different from the contemporary usage coined by W. E. Johnson.

7 In my view, transcendental determinacy is both a metaphysical and epistemological notion: an object or a relation is determinate to the extent that we can have a priori knowledge of it. For a helpful discussion of the metaphysical and epistemological import of the determination of appearances in the CPR, see Watkins (2005: ch. 3).

8 'Appearances (Erscheinungen) to the extent that as objects they are thought in accordance with the unity of the categories are called phenomena (Phaenomena)' (A249). While Kant tends to use the term Erscheinungen for all appearances in the CPR, he talks about the distinction between apparentia (the undetermined object of empirical intuition) and phaenomenon (the object of experience) in his Inaugural Dissertation (2: 394). For more on this distinction, see Longuenesse (I998: 24-6).

9 Note that I am here ignoring the potential synthesis of raw sensations into spatiotemporal representations (intuitions), and treating intuitions as the baseline for determinacy, as Kant often does. Nonetheless, it seems technically correct to me to say that human intuitions are, in turn, determinate with regard to the forms of our sensibility, space and time.

Io As Karl Ameriks puts it, appearances can be seen as extensionally equivalent to phenomena, but intensionally different from them. (2003: 78 ).

I I It should, however, be noted that intuitions, while in Kant's words 'undetermined', are objective insofar as they have a spatiotemporal form. Indeed, Kant repeatedly emphasizes that space and time are 'objectively valid' with regard to everything that can come before us $\left(\mathrm{A}_{2} 8 / \mathrm{B}_{44}, \mathrm{~B}_{52}\right)$.

I2 In the third Critique, Kant draws a distinction between 'objective sensations', which are of objects of perception (and thus give rise to empirical judgements), and 'subjective sensations', which are of feelings (and thus give rise to aesthetic judgements). This distinction does not concern us here, and, in any case, even a so-called objective sensation is still a subjective representation in that it is not determined by any forms of experience (CPJ, 5: 206-7).

I3 Kant also speaks of intuition as 'immediate representation', but I take this to be primarily meant to distinguish the faculty of intuition in general, by which an object is immediately given (whether spatiotemporally or otherwise), with the faculty of understanding, through which an object is mediately (discursively) thought.

I4 Strictly speaking, however, the modal categories have a role to play at each level in the progress to experience, and the relational principles are the truly only 'dynamical' ones. At the outset of his account of the Postulates, Kant observes that it is a peculiar quality of the modal categories that 'as determination of the object they do not augment the concept to which they are ascribed in the least, but rather express only the relation to the faculty of cognition' (A219). As such, I will limit my discussion of the dynamical principles to the Analogies of Experience.

I 5 I am using 'formally necessary' in the sense formulated by Nick Stang (20II: 446), whereby '[i]t is formally necessary that $\mathrm{p}$ just in case it is incompatible with our forms of experience that not-p'.

I6 For the most part, Kant uses 'actuality' (Wirklichkeit) and 'existence' (Dasein) interchangeably (A $455, \mathrm{~A}_{225}, \mathrm{~B}_{273}$ ). In fact, when he first presents the table of categories, Kant characterizes the second moment of the category of modality as 
'Existence - Non-existence' (A80/Bro6) and only in his account of the Postulates characterizes it as 'actuality'.

I7 To say that perceptions are partially determined by the categories is not necessarily to commit to either a conceptualist or a nonconcepualist reading of Kant. The conceptualist (cf. Ginsborg 2008 and Griffith 20I0) argues that all objective content of representation (including that of intuitions) requires the mediation of concepts while the nonconceptualist (cf. Allais 2009 and Tolley 2013) argues that empirical intuition can present us with objective content of particulars independent of the mediation of concepts. To argue that the objective content of perception (as apprehended intuition) is partially determined by the categories is not to take a position either way with regard to whether the most minimal form of this content (i.e. that presented in intuitions) is mediated by concepts or not. Accordingly, the categorial syntheses spoken of throughout this paper are those on whose occurrence both conceptualists and nonconceptualists agree: that is, those involving the subsumption of intuitions under concepts. Thus when, for example, I say that perception is not guided by the concept of relation, I mean this with regard to the 'latter end' of the epistemic process - to borrow Longuenesse's phrasing (2000: 96). I do not mean to deny the possibility of a more 'primitive' synthesis of the sensible manifold in accordance with the concept of relation. Thanks to an anonymous referee at this journal for pressing me to clarify this point.

I8 As Kant's own examples will show, however, not all judgements of perception are capable of being 'transformed' into judgements of experience through the employment of the 'special concepts' of the understanding.

I9 Michael Friedman makes the same point in the context of his illuminating study of Kant's treatment of Newton's laws of motion: '[T] he analogies constitute the mechanism for transforming mere appearance into objective experience.' See Friedman (I994: I84-5). My claim here should not be taken to mean that the mathematical categories play no part in the making of judgements of experience, as I am only talking about the conversion of judgements of perception into judgements of experience. My argument is that this conversion is made possible by the relational categories alone. Of course, insofar as all judgements of experience begin as judgements of perception, they rely on (i.e. are made possible by) the mathematical categories as well.

20 Beatrice Longuenesse observes that in saying 'The air is elastic' I may mean, 'Air feels resistant to compression', thereby meaning it as a mere judgement of perception. See Longuenesse (I998: I74).

2 I Cf. Kant's introduction to the Metaphysical Foundations of Natural Science: 'through concepts of the understanding, an object is determined with respect to one or another function of judgement' (4:475).

22 For more on Kant's account of the condition of hypothetical judgements see Longuenesse (I998: IOI-2).

23 In very rough terms, these judgements can be envisioned as parts of a syllogism, wherein the category acts as a universal rule, the transcendental schema as the middle term, and the perception as the particular instance which is to fall under the universal rule through the mediation of the schema. See Allison (2004: 213).

24 Robert Hanna makes the same point when he states that the syntactic well-formedness (grammatical correctness) of judgements is a necessary but not sufficient condition for their objective validity (2010: 229-3 I). Longuenesse likewise observes, in her discussion of the Prolegomena examples, that 'the mere form of [hypothetical] judgement is not sufficient to insure that the relation [of causality] does hold of the empirical objects "in themselves"' (I998: I78). 
25 There are varying views on the relation between the two kinds of logic. The view held by Cohen and Ueberweg that general logic deals with analytic judgements and transcendental logic with synthetic judgements has long been rejected, and it is generally agreed that general logic contains the rules for all use of the understanding (cf. B76). There are, however, disagreements regarding the scope or domain of transcendental logic vis-à-vis general logic. While some (cf. Paton 1957; Tonelli I994) restrict it to objects of sensibility, others (cf. Rödl 2006; Tolley 20I2) argue that its domain is as expansive as that of general logic. To the extent that this disagreement has a bearing on my argument, it concerns whether the forms of judgement can be utilized without subsumption under the categories (specifically, that of relation). The Prolegomena's account of judgements of perception clearly implies that they can. Whether this notion (i.e. that of a judgement not employing the categories, specifically, that of relation) is coherent within the larger framework of the CPR is one of the things the present paper seeks to address.

26 To reiterate the point made in note $\mathrm{I} 7$, here I am not denying the possibility of an earlier categorical synthesis in the process of cognition, one by which the sensible manifold is conceptualized (though I am not taking a position on whether or not such synthesis takes place). My claim that 'all and only judgements of experience utilize the relational categories' is concerned with the subsumptive use of the categories only.

27 The Analogies, as the 'actual laws of nature', carry necessity and universality with them insofar as they determine the existence and relation of appearances. As Eric Watkins observes, 'the notion of necessity involved in the laws of nature is that of determination, which Kant understands as the positing of a reality or property to the exclusion of its opposite' (2014: 482).

28 In the Mrongovius lectures on metaphysics dating to $1782-3$, Kant again draws a distinction between judgements of perception and judgements of experience, and goes on to state that for a judgement to have objective validity, the 'sequence of perceptions must be determined according to rules, i.e., be necessary'. He identifies this rule with the principle of sufficient reason, and declares it to be the ground of the possibility of experience (29: 8I 5). In the System of Principles, likewise, the principle of sufficient reason is declared to be a synthetic a priori principle, equivalent to the second analogy of experience, and the ground of possible experience (B246).

29 It should be noted that these sensations, except for pleasure/displeasure, would still be considered 'objective' sensations by the third Critique account (CPJ, 5: 206-7). It seems to me, however, that the third example from the first set ('wormwood is repugnant') could be characterized as an aesthetic judgement instead of an empirical one, since the feeling it expresses (displeasure) is a subjective sensation.

30 By 'singular judgement' I have in mind judgements whose quantity, as per the table of judgements (A70/B95), is singular (as opposed to particular or universal). That is, judgements of the form 'This $x$ is F.'

3 I Both Friedman and Longuenesse characterize the second group of judgements of perception as inductive generalizations. Friedman argues that, for Kant, Kepler's laws would have counted as judgements of perception, since they are not grounded in a priori laws of nature (i.e. the Analogies). As such, they only have a hypothetical or inductive status, in contradistinction to Newton's law of universal gravitation, which admits of a 'material' universality and necessity (I994: $175-83$ ). Longuenesse, likewise, observes that the universality expressed by the second group of judgements of perception is 'mere inductive generality' (I 998: I 72 note I I ). In making these judgements, 'I may suspend at least provisionally any claim to objective validity ... and just state how things seem to me' (I998: I74). 
32 For Kant's exposition of the method and goal of the Prolegomena see 4:263 and 4:274, respectively.

33 Longuenesse goes on to argue that in the first case (i.e. the Humean picture) all judgements would be like judgements of perception (I998: I88). I would add a qualification: whether Humean judgements are equivalent to Kantian judgements of perception would depend on whether they rely on the synthesis of apprehension, which has been shown to be an essential part of Kantian judgements of perception. In the absence of the synthesis of apprehension, judgements formed in accordance with empirical associations would at most be able to connect simple, unprocessed sense data. Given that Hume leaves room for complex ideas and impressions, his account seems to implicitly presuppose some synthesis of apprehension whereby complex representations are unified. It could, in the end, turn out that Humean judgements are equivalent to Kantian judgements of perception, but only if we allow that Hume's account implicitly relies on some sort of synthesis.

I am grateful to Nick Stang for helpful discussions and invaluable comments on earlier drafts of this paper. I also thank two anonymous referees for this journal for their detailed feedback.

\section{References}

Allais, L. (2009) 'Kant, Non-Conceptual Content, and the Representation of Space'. Journal of the History of Philosophy, 47(3), 383-4I 3 .

Allison, H. E. (1983) Kant's Transcendental Idealism. New Haven: Yale University Press.

— (2004) Kant's Transcendental Idealism (rev. and enlarged edn). New Haven: Yale University Press.

- (2015) Kant's Transcendental Deduction: An Analytical-Historical Commentary. Oxford: Oxford University Press.

Ameriks, K. (2003) Interpreting Kant's Critiques. Oxford: Oxford University Press.

Cassirer, E. (1953) Substance and Function and Einstein's Theory of Relativity. Trans William Curtis Swabey and Marie Taylor Swabey. Chicago: Open Court Publishing Co.

Friedman, M. (1994) Kant and the Exact Sciences. Cambridge, MA: Harvard University Press.

Ginsborg, H. (2008) 'Was Kant a Nonconceptualist?'. Philosophical Studies, I37(I), $65-77$.

Griffith, A. (2010) 'Perception and the Categories'. European Journal of Philosophy, 20(2), I-30.

Guyer, P. (1987) Kant and the Claims of Knowledge. Cambridge: Cambridge University Press.

Hanna, R. (2010) 'Kant, Truth, and Human Nature'. British Journal for the History of Philosophy, 8(2), 225-50.

Höffe, O. (I994) Immanuel Kant. Trans. Arthur Marshall Farrier. Albany, NY: State University of New York Press.

Hume, D. (1993) An Enquiry Concerning Human Understanding. Ed. E. Steinberg. Indianapolis: Hackett Publishing.

Kant, I. (I902-) Kants Gesammelte Schriften. Ed. Königlich Preussische Akademie der Wissenschaften, vols I-29. Berlin: De Gruyter.

- (199I-) The Cambridge Edition of the Works of Immanuel Kant. Ed. P. Guyer and A. Wood. Cambridge: Cambridge University Press.

Longuenesse, B. (1998) Kant and the Capacity to Judge: Sensibility and Discursivity in the Transcendental Analytic of the Critique of Pure Reason. Princeton: Princeton University Press.

(2000) Kant on the Human Standpoint. Cambridge: Cambridge University Press. 
Prauss, G. (197I) Erscheinung bei Kant. Berlin: De Gruyter.

Paton, H. J. (I957) 'Formal and Transcendental Logic'. Kant Studien, 49(I-4), 245-63.

Rödl, S. (2006) 'Logical Form as a Relation to the Object'. Philosophical Topics, 34(I), $345-69$.

Smith, N. K. (1918) A Commentary to Kant's Critique of Pure Reason. London: Macmillan. Stang, N. (2OII) 'Did Kant Conflate the Necessary and the A Priori?' Nô̂s, 45(3), 443-7I. Tolley, C. (2OI2) 'The Generality of Kant's Transcendental Logic'. Journal of the History of Philosophy, 50(3), 4I7-46.

- (2013) 'The Non-Conceptuality of the Content of Intuitions: A New Approach'. Kantian Review, I 8(I), I07-36.

Tonelli, G. (I994) Kant's Critique of Pure Reason within the Tradition of Modern Logic. Zurich: Georg Olms.

Watkins, E. (2005) Kant and the Metaphysics of Causality. Cambridge: Cambridge University Press.

(20I4) 'What is, for Kant, a Law of Nature?' Kant-Studien, I05(4), 47I-90. 